\title{
Scurvy and vitamin C deficiency in Crohn's disease
}

\author{
B. D. LINAKER \\ M.B., B.S., M.R.C.P. \\ Department of Medicine, Hope Hospital \\ (University of Manchester School of Medicine), Salford M6 8HD
}

\begin{abstract}
Summary
A case of scurvy presenting in a patient with Crohn's disease is reported. A normal response to replacement therapy is seen. Vitamin C (ascorbic acid) deficiency was found in 7 out of 10 patients with clinically quiescent Crohn's disease, 4 of whom had an adequate oral intake of vitamin $C$. There was no significant difference in oral intake between patients with Crohn's disease and matched controls but there was a significant difference $(P<0.001)$ in leucocyte ascorbic acid levels. It is recommended that patients with Crohn's disease be screened for vitamin C deficiency and receive prophylactic vitamin $\mathrm{C}$ supplements daily.
\end{abstract}

\section{Introduction}

Several vitamin deficiencies have been described in association with Crohn's disease, including the $B$ complex, $B_{12}, D$ and $K$. Other deficiencies may include iron, folic acid, calcium, magnesium, sodium, potassium or zinc (Avery Jones, Gummer and Lennard-Jones, 1968; Donaldson, 1973; Bockus, 1976).

As recommended treatment may include low residue diets or parenteral nutrition, both of which have a low vitamin $\mathrm{C}$ content, and the disease itself often causes malabsorption, it seems possible that vitamin $\mathrm{C}$ deficiency may be relatively common in Crohn's disease. It has been shown by Gerson and Fabry (1974) that vitamin C (ascorbic acid) concentrations in patients with Crohn's disease are decreased compared to normal controls. They postulated that fistula formation could be due to local ascorbate deficiency. Hughes and Williams (1978) have recently reported low concentrations of leucocyte ascorbic acid (LAA) in Crohn's disease. There are no reports in the literature of scurvy in association with Crohn's disease. The following case is thus reported.

\section{Case report}

A 28-year-old female with small bowel and colonic Crohn's disease (radiological and histological evidence) of 3 years' duration attended outpatients with a 3-month history of malaise, aching joints and general weakness and a 2-month history of spontaneous painful bruises on the thighs and lower legs. Clinically the Crohn's disease was quiescent and she had received no drug therapy for approximately one year. On examination she was well nourished. There were some petechiae and ecchymoses on the lower limbs only. The remainder of the skin was normal and she was edentulous with normal gum appearance. These skin appearances suggested early scurvy.

The following investigations were normal: full blood count, platelets, prothrombin time, partial thromboplastin time, fibrinogen concentration, fibrinogen degradation product titre, ESR, urea, electrolytes, serum proteins, serum and red cell folate, vitamin $\mathbf{B}_{\mathbf{1 2}}$ and calcium. However, leucocyte ascorbic acid concentration was $25 \mathrm{nmol} / 10^{8}$ whit blood cells (normal 119-301 nmol/10 $\mathrm{WBC}$ ). The safe antiscorbutic level is $85 \mathrm{nmol} / 10^{8} \mathrm{WBC}$ (Hughest and Williams, 1978).

Oral vitamin C, $600 \mathrm{mg}$ daily for one week rapidly led to resolution of the skin lesions and nonspecific complaints of malaise, joint ache and weakness. The treatment was continued at a lower dose of $100 \mathrm{mg} /$ day. Subsequent dietary assessment showed a very low daily intake of ascorbic acid of less than $10 \mathrm{mg}$ daily. This was due to a self-imposed low residue diet adopted by the patient because of occasional colicky abdominal pains.

In view of this experience, it was decided to examine the next 9 out-patients with proved Crohn's disease for evidence of scurvy. Assessment of the ascorbic acid status, dietary intake of vitamin $\mathrm{C}$ and the macroscopic extent of the disease was also done, in order to establish whether subclinical ascorbic acid deficiency was as common in this group of Crohn's cases as in other series.

\section{Methods}

Leucocyte ascorbic acid, which most reliably reflects the state of tissue saturation (Burns, 1975), was measured by the method of Denson and Bowers (1961). The normal range of this method measures the ascorbic acid content of the buffy coat, i.e. leucocytes and platelets and is referred to as the 
Scurvy in Chron's disease
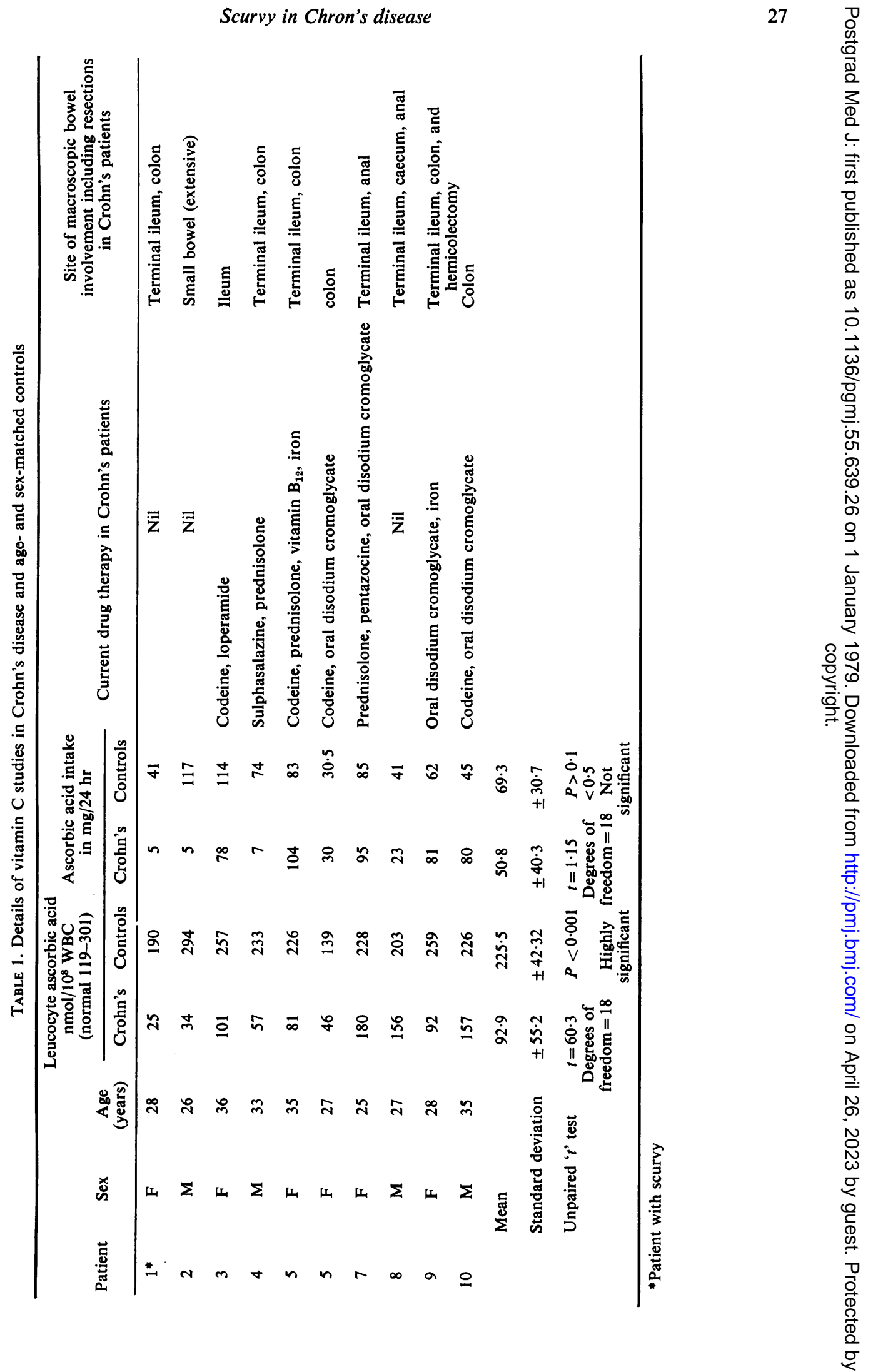
'leucocyte ascorbic acid'. This range was used. However, later work by Gibson, Moore and Goldberg (1966) altered the normal range by measuring ascorbic acid in leucocytes only. Conversion factors based on leucocyte and platelet counts can be applied to results obtained by Denson and Bowers' method for specific leucocyte ascorbic acid levels.

The dietary intake of vitamin $\mathrm{C}$ was estimated by trained dieticians using McCance and Widdowson food composition tables. A control group of healthy adults with no evidence of bowel disease and matched for age and sex was included, and dietary assessment and LAA measurement was performed in them. Comparisons between controls and patients were performed with the unpaired ' $t$ ' test.

\section{Results}

The results are shown in Table 1 .

No clinical evidence of scurvy was detected in any of the 9 patients examined. The Crohn's disease was clinically quiescent in all patients apart from patient 7 , who had colicky abdominal pain requiring intermittent pentazocine.

Seven of 10 patients had low LAA levels. Of these, 4 had a low dietary intake by any criteria. Two of the patients had LAA levels below the safe antiscorbutic concentration of $85 \mathrm{nmol} / 10^{8}$ WBC despite an adequate diet.

Overall, the concentration of LAA in Crohn's patients was significantly lower $(P<0.001)$ than in matched signals. There was no significant difference $(P>0.1,<0.5)$ in oral intake of vitamin $C$ between controls and patients with Crohn's disease.

\section{Discussion}

James Lind (1753) has probably recorded the best clinical description of scurvy. He stated that the first sign of cutaneous bleeding was often to be found in the lower thighs just above the knees. Large spontaneous bruises almost always appear first on the legs. This was the case in the present patient who also exhibited the early non-specific symptoms of scurvy, namely fatigue, malaise, lassitude and joint aching. Oral lesions occur almost exclusively in patients who have retained their own teeth (Van Itallie, 1977). As the patient was edentulous it is not surprising that she had no oral lesions and none of the gum changes often seen in this condition. It has been said that the LAA level falls to zero just before scurvy develops (Herman, Stibel and Greene, 1976) and in this, the present patient was not typical although the level of $25 \mathrm{nmol} / 10^{8} \mathrm{WBC}$ was far below the 'safe' antiscorbutic level of $85 \mathrm{nmol} / 10^{8}$ WBC (Hughes and Williams, 1978).

Vitamin C deficiency can lead to malaise, anorexia weakness, lassitude, bone and joint aching and psychological changes. It causes poor collagen for- mation due to failure to convert proline to hydroxyproline and failure of synthesis of chondroitin sulphate, an important constituent of ground substance. Wounds therefore heal poorly. There is a failure to utilize iron and convert folic acid to folinic acid with the potential to develop folate deficiency and anaemia (Schrimshaw, 1975). Some of these features are seen in Crohn's disease and it is possible that deficiency of vitamin $\mathrm{C}$ may be a factor in their aetiology.

However, it should be noted that vitamin $\mathrm{C}$ deficiency is not specific to Crohn's disease and is well recognized in conditions which damage the body, such as burns, fractures or surgical operations. These lead to rapid disappearance of the reduced vitamin (Davidson et al., 1975). Deficiency is also seen in a wide variety of chronic illnesses, especially sepsis, neoplastic disease, etc., and is thought to be due to increased utilization of the vitamin (Burns, 1975; Latner, 1975).

Vitamin $C$ is a simple sugar with a molecular weight of 176. It is water soluble and an acid. It has been thought to be absorbed throughout the small intestine by passive diffusion (Nicholson and Charnock, 1942), but recent work by Stevenson (1974) and confirmed by Mellors, Nahrwold and Rose (1977) shows an active transport mechanism of absorption by the ileum. Even after majoro resections of the small intestine resulting in a states resembling starvation, absorption of vitamin $\mathrm{C}$ iso still maintained and deficiency is not usually $a$ problem (Stewart and Booth, 1964; Preston and Ascunction, 1968). However, LAA levels have been found to be decreased in steatorrhoea and clinical evidence of vitamin $\mathrm{C}$ deficiency has been reported (Williamson, Goldberg and Moore, 1967). The present patients had not had small bowel resections and radiology had not shown internal fistulae. There was nothing to suggest steatorrhoea clinically, although faecal fats were not measured.

Gerson and Fabry (1974) suggested that low LAA concentration in Crohn's cases could be related to low dietary intake. There is controversy over the adequate minimum daily LAA intake for an adult. The United Kingdom recommended daily intake is $30 \mathrm{mg}$ or more, while the Food and Nutrition Board of the National Research Council, U.S.A., has progressively decreased the recommended daily intake from $75 \mathrm{mg}$ in 1943 to $45 \mathrm{mg}$ in 1974 . On the latest criteria, therefore, only 5 cases were having an inadequate dietary intake of vitamin C. Although the lowest LAA results correlated with the lowest dietary intake, there were 3 patients with low LAA concentrations on an adequate dietary intake by all standards, and 4 patients with low LAA concentrations on adequate dietary intake by United Kingdom standards. 
Patients with colonic involvement alone are unlikely to develop vitamin $\mathrm{C}$ deficiency due to malabsorption. However, patient 6 had colonic involvement only, an adequate dietary intake by United Kingdom standards and a low LAA. It is interesting that the site of the Crohn's disease apparently bears no relation to the low LAA levels observed. However, malabsorption can occur in apparently normal bowel and thus the site of macroscopic Crohn's disease involvement is probably not relevant.

It is possible that there is an increased demand for vitamin C in Crohn's disease rather than malabsorption. It may be possible to correlate activity or severity of the disease to vitamin $\mathrm{C}$ levels, but this will require more study. There is no evidence that codeine phosphate, sulphsalazine, disodium cromoglycate or steroids affect LAA levels. Large doses of vitamin $\mathrm{C}$ are said to have no deleterious side effects (Burns, 1970).

In view of the findings of vitamin $\mathrm{C}$ deficiency in this and other studies, it is recommended that regular vitamin $C$ supplements (50-100 $\mathrm{mg}$ daily) should be given to all patients with Crohn's disease to prevent overt or subclinical vitamin $\mathrm{C}$ deficiency and possibly improve their sense of well being. In proved deficiency a dose of $200-1000 \mathrm{mg}$ daily initially should be satisfactory (Losowsky, Walker and Kelleher, 1974).

\section{Acknowledgments}

I would like to thank Dr R. B. McConnell for permission to report this case, Professor L. A. Turnberg for his helpful criticism of the paper, Miss Dymock, Miss McGraw and Mrs Ellams for assessment of vitamin $\mathbf{C}$ intake and Mrs $\mathbf{J}$. Coulston for secretarial help.

\section{References}

AVery Jones, F., Gummer, J.W.P. \& Lennard-Jones, J.E. (1968) Clinical Gastroenterology, 2nd edn, p. 612. Blackwell Scientific Publications, Oxford.

BockUS, H.L. (1976) Gastroenterology, vol. II, 3rd edn, pp. 574-579. W. B. Saunders Co., Philadelphia.

Burns, J, (1970) The Pharmacological Basis of Therapeutics, Eds Goodman, L.S. \& Gilman, A. 4th edn, p. 1667. MacMillan, Toronto.
Burns, J. (1975) The Pharmacological Basis of Therapeutics Eds Goodman, L.S. \& Gilman, A. 5th edn, p. 1567. MacMillan, Toronto.

Davidson, S., Passmore, R., Brock, J.F. \& Truswell, A.S. (1975) Human Nutrition and Dietetics, 6th edn, p. 158. Churchill Livingstone, Edinburgh.

DENSON, K.W. \& BowERS, E.F. (1961) The determination of ascorbic acid in white blood cells. Clinical Science, 21, 157.

Donaldson, R.M. (1973) Gastrointestinal Disease (Eds. Sleisenger, M.H. \& Fordtran, J.S.), 1st edn, pp. 899-900. W. B. Saunders, Philadelphia.

Gerson, C.D. \& FABRY, E.M. (1974) Ascorbic acid deficiency and fistula formation in regional enteritis. Gastroenterology, $67,428$.

Gibson, S.L.M., Moore, F.M.L. \& Goldberg, A. (1966) Measurement of leucocyte ascorbic acid. British Medical Journal, 1, 1152.

Herman, R.H., Stifel, F.B. \& Greene, H.L. (1976) Disorders of the Gastrointestinal Tract, Disorders of the Liver, Nutritional Disorders (Ed. Dietschy, J.M.), vol. 1, pp. 373-374. Grune \& Stratton, New York.

Hughes, R.G. \& Williams, N. (1978) Leucocyte ascorbic acid in Crohn's disease. Digestion, 17, 272.

LATNer, A.L. (1975) Clinical Biochemistry, 7th edn, p. 824. W. B. Saunders, Philadelphia.

LiND, J. (1753) A Treatise of the Scurvy, reprinted 1953. Edinburgh University Press.

LosowsKy, M.S., WAlKer, B.E. \& Kelleher, J. (1974) Malabsorption in Clinical Practice, p. 67. Churchill Livingstone, Edinburgh.

Mellors, A.J., Nahrwold, D.L. \& Rose, R.C. (1977) Ascorbic acid flux across mucosal border of guinea-pig and human ileum. American Journal of Physiology, 233 (5), E374.

Nicholson, J.T.L. \& ChoRnock, F.W. (1942) Intubation studies of the human small intestine XXII - An improved technique for the study of absorption: its application to ascorbic acid. Journal of Clinical Investigation, 21, 505.

Preston, F.W. \& Ascunction, Z.G. (1968) Management after massive resection of the intestine. Surgical Clinics of North America, 48, 931.

SCHRIMSHAw, N.S. (1975) Textbook of Medicine, (Eds Beeson, P.B. \& McDermott, W.), 14th edn, p. 1373. W. B. Saunders, Philadelphia.

SteVenson, N.R. (1974) Active transport of L-ascorbic acid in the human ileum. Gastroenterology, 67, 952.

STEWART, J.S. \& Booth, C.C. (1964) Ascorbic acid absorption in malabsorption. Clinical Science, 27, 15.

Van Itallie, T.B. (1977) Principles of Internal Medicine, 8th edn, pp. 459-461. McGraw Hill, New York.

Williamson, J.M., Goldberg, A. \& Moore, F.M.L. (1967) Leucocyte ascorbic acid levels in patients with malabsorption or previous gastric surgery. British Medical Journal, $2,23$. 